\title{
Effect of abutment type and tightening sequence on torque maintenance capacity after mechanical cycling in splinted im- plant-supported restorations
}

\author{
Leonardo Jiro Nomura Nakano ${ }^{1}$, Laís Carolina Landim Gomes ${ }^{1}$, Talita Suelen de Queiroz ${ }^{1}$ and Tarcisio José de \\ Arruda Paes-Junior ${ }^{2, *}$ \\ 1 Institute of Science and Technology, São Paulo State University UNESP, São José dos Campos 12245-000,
Brazil 1; jiro.nakano@unesp.br; landim.gomes@unesp.br; queiroz.tts@gmail.com; tarcisio.paes@unesp.br
* Correspondence: queiroz.tts@gmail.com
}

\begin{abstract}
The aim of this study was to compare the screw removal torque of mini conical prosthetic components and straight trunnion of indexed morse taper implants, after mechanical cycling. The sample consisted of 40 implants and 20 mini-conical prosthetic components (MC group) and 20 straight trunnion components (ST group). Each group consisted of 10 specimens, with 2 implants in each, and cobalt-chromium metallic crowns were screwed into each sample. The components of the MC group received a torque of $20 \mathrm{~N} . \mathrm{cm}$ with a digital torque wrench and after 10 minutes were retightened with the same value as the initial torque. The components of the ST group received a torque of 30 N.cm, with a digital torque wrench and after 10 minutes, they were retightened with the same value. The screws of the respective crowns of the two groups received a torque of $10 \mathrm{~N} . \mathrm{cm}$ and after 10 minutes were retightened with the same value. Each group was subjected to the fatigue test in a mechanical cycler at 2.000 .000 cycles, with a load of $250 \mathrm{~N}$ and frequency of $4 \mathrm{~Hz}$. At the end of the fatigue test, the loosening torque of each screw of the specimens was measured through a digital torque wrench. The data were analyzed by two-way ANOVA and Tukey test. In both groups, there were loss of torque. The results showed no statistic difference between MC and ST groups.
\end{abstract}

Keywords: Dental Implants; fatigue; mechanical tests; torque

\section{Introduction}

Dental implants have been widely used in oral rehabilitation to replace one or more missing teeth with satisfactory survival rates. Although, adverse biological responses and complications in prosthetic restorations can occur, such as loss of torque in screws or the fracture of them [1,2].

The loss or decrease in the torque of the retention screw of an implant-supported prosthesis can be caused by different factors such as a low preload on the screw, failures after initial insertion and settle; prosthetic component and dentist-induced variables during torque $[4,5]$.

Implant-component connections have been considered a very important factor in the success of implant treatment [2]. During chewing, there is load distribution along the implant long axis, and micro-movements can occur in these connections, contributing to the loss of torque in the screws, as well as the misfit of prosthetic restorations [5].

In the oral environment, chewing forces act on the prosthetic restorative materials promoting mechanical cyclic impulses, which can be simulated in the laboratory by mechanical cycling, which reproduces physiological conditions during chewing [6,7]. 
Implant and abutment manufacturers have sought to improve the design of the morse taper system to better adapt the implant-abutment interface. Thus, they developed the Indexed Morse taper system, which features an internal anti-rotational device, allowing greater stability of the set by promoting greater contact of the prosthetic component with the implant cone $[8,9]$.

In all implant systems, the implant-component union determines the mechanical integrity, strength, and stability of the assembly. Systems with internal connection were created to minimize screw torque loss and possible fractures commonly found in external hexagons. A biconical connection mechanism effectively results in a high protection against excessive loads and reduces the screw loosening [10].

This study aims to compare the torque maintenance capacity of two different prosthetic components and implant sequence after mechanical cycling.

\section{Materials and Methods}

For this study, 40 Indexed Morse taper (IMT) implants of $4.0 \mathrm{~mm} \times 11 \mathrm{~mm}$ were selected, which were divided into two groups: Group MC, of the mini conical prosthetic abutments and group ST, of the straight trunnion prosthetic abutments. Each group has a sample of 10 specimens, with 2 implants in each body (to simulate multiple prostheses). Each body of the two groups was numbered from 1 to 10.

Twenty specimens were made, which consisted of PVC tubes with $25 \mathrm{~mm}$ in diameter cut into 20 equal parts of $12 \mathrm{~mm}$ in height. Equal parts 1:1 of the Axson polyurethane resin were mixed and placed in the barrel up to the edge. The final cure was awaited to install the implant. In this body, 2 alveoli were made using the sequence of drills indicated. The perforations were $3 \mathrm{~mm}$ apart and then 2 implants were installed with a manual torque wrench and $3 \mathrm{~mm}$ of exposed threads according to ISO 148018:2007 standard [11] (Figure $1)$.

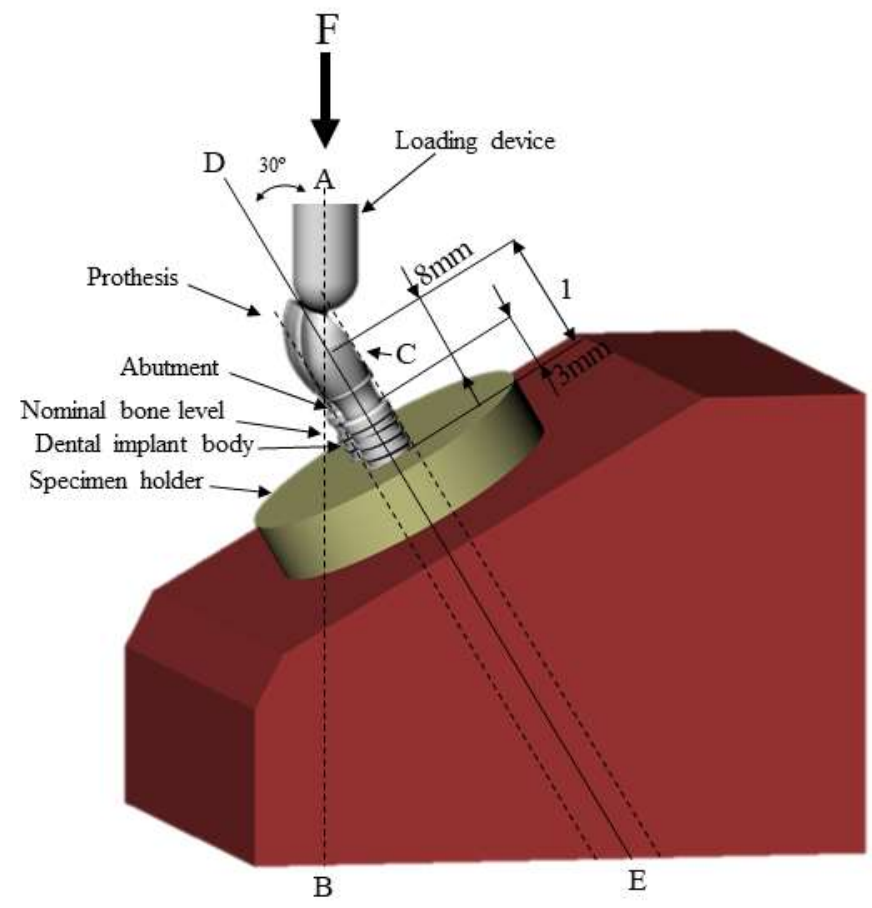

Figure 1. Schematic of test setup according to the ISO 14801 recommendations. 
Then, 20 standardized metallic frameworks were cast in $\mathrm{Ni}-\mathrm{Cr}$ (10 for the miniconical trunnion and 10 for the straight trunnion). After each prosthesis was ready, the abutments were screwed with the implants already attached, forming the implantabutment-prosthesis set (Figure 2).

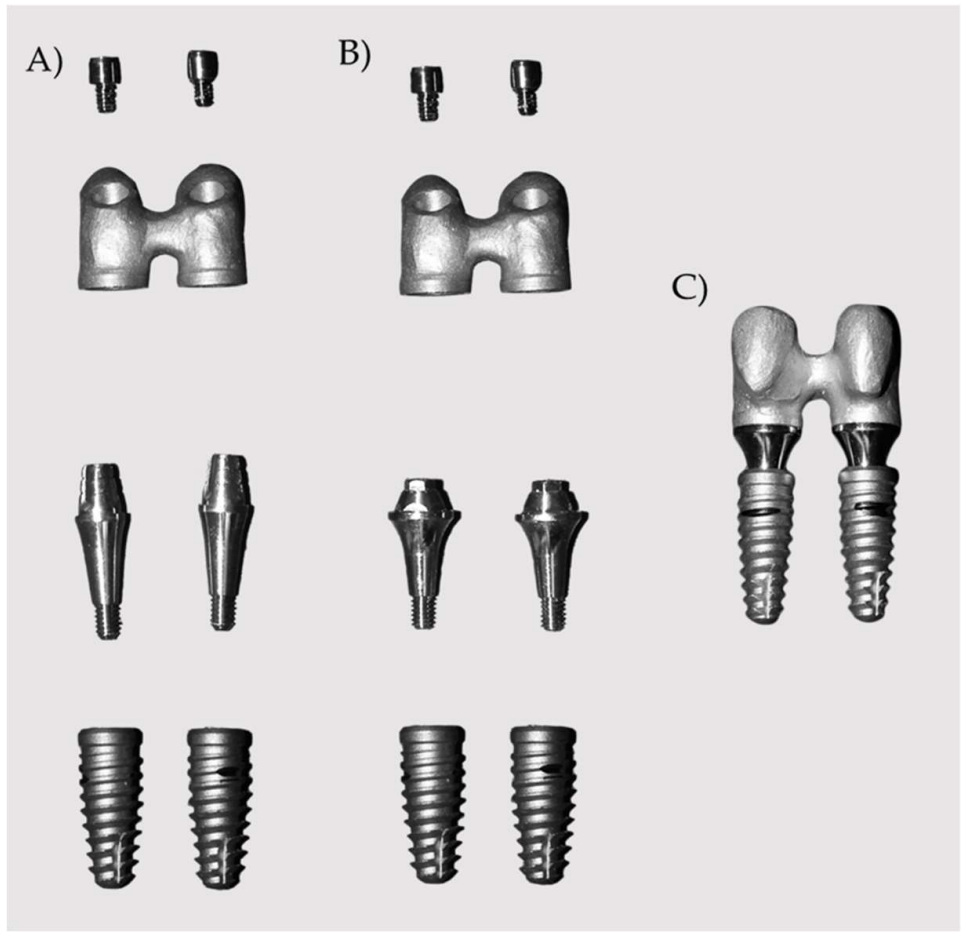

Figure 2. Study design showing the components used in each group. A) Implant set, straight trunnion, metallic framework and retaining screw of the ST group; B) Implant set, mini-conical abutment, metallic framework, and group MC retention screw; C) Implant-abutment-prosthesis set.

The specimens from each group were positioned with a $30^{\circ}$ inclination of the implant in relation to the ground (ISO 14801:2007) [11]. Each group was placed in the Erios Mechanical Fatigue Simulator and a $60 \mathrm{~mm}$ tip was placed over each sample with a load of $250 \mathrm{~N}$ and frequency of $4 \mathrm{~Hz}$, in the axial direction. The specimens were subjected to $2 \times 106$ cycles. After the cycling period ended, the screw loosening torques were measured in both groups with the digital torque wrench Instrutherm TQ-680. Data were statistically analyzed using two-way ANOVA with $\alpha=5 \%$, considering the presence or absence of mesh (Minitab 17, Pennsylvania, USA).

\section{Results}

The descriptive statistics obtained in the experiment are represented in the table 1 and figure 2.

Each of the abutments was checked for the condition of retaining the prosthesis. This condition was evaluated at the initial step of abutment installation (preload), after $10 \mathrm{~min}$ to respect the screw elastic recovery and after aging due to mechanical fatigue (Torque loss). As both abutments are indicated for fixed prosthesis of several elements, two implants were installed per specimen and the measurements were verified in each one of them. The implant 1 was the first to be tightened and the first to be measured in all conditions and the implant 2 was the second one measured in the sequence. In this 
study, the implant sequence was considered as an analysis factor during the statistical approach (Tables 2-4).

\section{Boxplot of Torque loss}

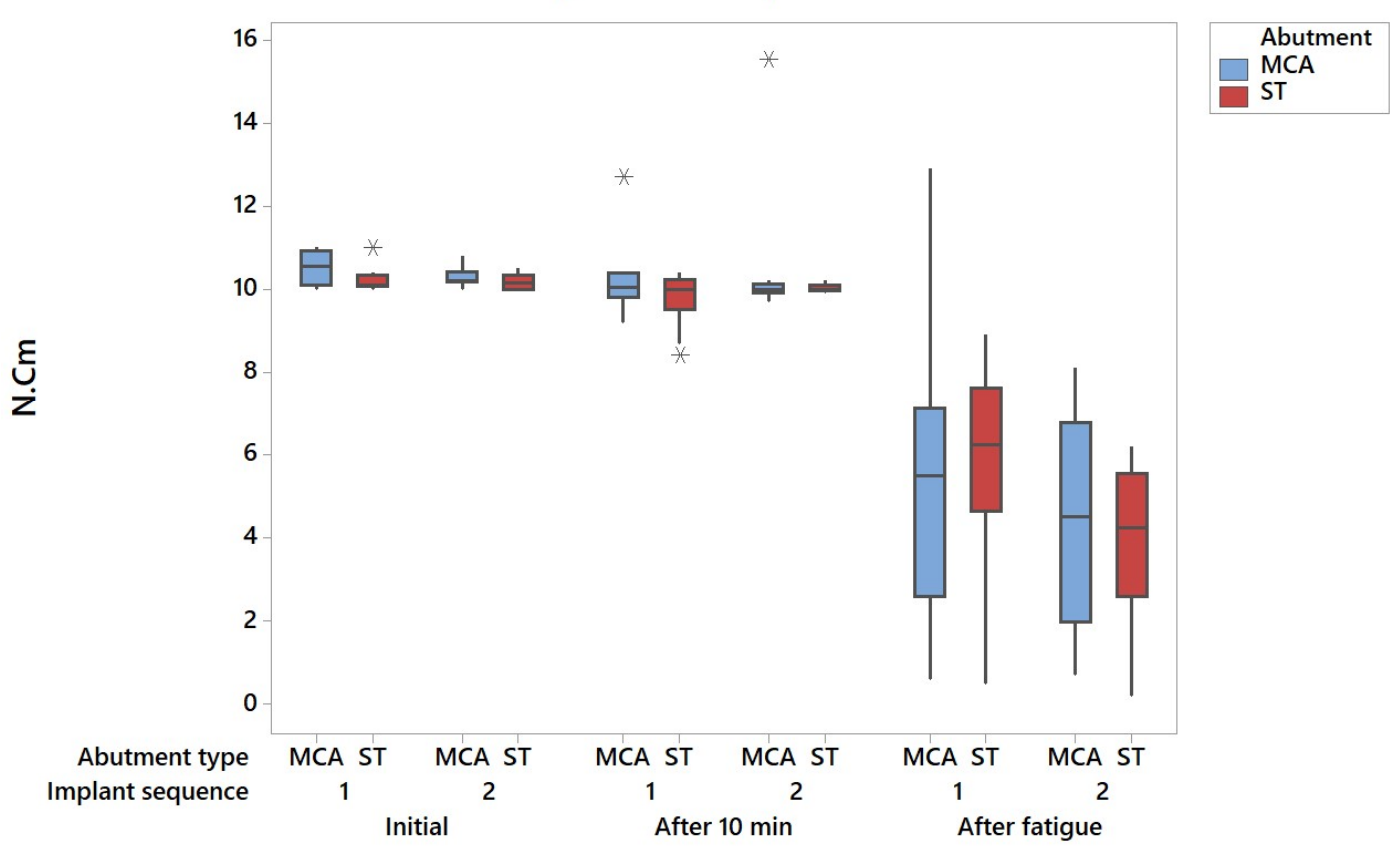

Figure 3. Boxplot of torque measurement according to the implant sequence, abutment type and tightening moment.

Table 2. Two-way Analysis of Variance results of initial torque according to the Implant sequence and abutment type.

\begin{tabular}{lccccc}
\hline Initial torque & GL & SQ (Aj.) & QM (Aj.) & F value & P-Value \\
\hline Implant sequence & 1 & 0.19600 & 0.19600 & 2.28 & 0.140 \\
Abutment type & 1 & 0.36100 & 0.36100 & 4.19 & 0.068 \\
Implant sequence*Abutment type & 1 & 0.08100 & 0.08100 & 0.94 & 0.338 \\
Error & 36 & 3.09800 & 0.08606 & & \\
Total & 39 & 3.73600 & & & \\
\hline
\end{tabular}

Table 3. Two-way Analysis of Variance results of sitting torque according to the Implant sequence and abutment type.

\begin{tabular}{llllll}
\hline After 10 min & GL & SQ (Aj.) & QM (Aj.) & F value & P-Value \\
\hline Implant sequence & 1 & 0.7023 & 0.70225 & 0.64 & 0.431 \\
Abutment type & 1 & 2.2563 & 2.25625 & 2.04 & 0.162 \\
Implant sequence* Abutment type & 1 & 0.0123 & 0.01225 & 0.01 & 0.917 \\
Error & 36 & 39.7890 & 1.10525 & & \\
Total & 39 & 42.7598 & & & \\
\hline
\end{tabular}


Table 4 - Two-way Analysis of Variance results of torque loss according to the Implant sequence and abutment type.

\begin{tabular}{llllll}
\hline Torque after fatigue & GL & SQ (Aj.) & QM (Aj.) & F value & P-Value \\
\hline Implant sequence & 1 & 27.556 & 27.5560 & 3.72 & 0.062 \\
Abutment type & 1 & 0.036 & 0.0360 & 0.00 & 0.945 \\
Implant sequence*Abutment type & 1 & 1.369 & 1.3690 & 0.19 & 0.670 \\
Error & 36 & 266.378 & 7.3994 & & \\
Total & 39 & 295.339 & & & \\
\hline
\end{tabular}

Therefore, both abutments tested are equally capable of maintaining the torque of the prosthetic screw, even after chewing simulation.

\section{Discussion}

The present study compared the screw removal torques of mini-conical prosthetic components and straight trunnion of Indexed Morse taper implants, after mechanical cycling.

When torque is applied to the prosthetic screw, a preload is generated inside the screw which is nothing, but a frictional tension generated by the tightening between the screw threads and the implant's internal threads, and between the screw head and the abutment. This preload promotes the stabilization of the implant-abutment assembly and is proportional to the applied torque [11].

One mechanism that results in screw loosening right after the initial torque of prostheses on implants is the settling effect. This effect, which plays a critical role in screw stability, is the result of the presence of micro-roughness on the screw surface and the surface of the internal threads of the implants. Due to these uneven surfaces, no two surfaces are completely in contact with each other. The laying process takes place as there is a slight wear of the components, causing the two surfaces to come closer together. As a result, there is a $2 \%$ to $10 \%$ reduction in the preload value in the first minutes after the initial torque $[12,13,14]$.

Because of this preload loss soon after the initial torque application, it is recommended to tighten the abutment screw 10 minutes after the initial tightening [15]. The internal connection and abutments with anti-rotational and tapered designs have better resistance to screw loosening. Factors such as crown-implant ratio, presence of cantilevers, and occlusal overload increase the risk of screw loosening. To reduce the possibility of crown failure due to screw loosening, it is recommended to carry out frequently follow-ups and to retorque the prosthetic screw one month after the initial torque $[15,16,17]$.

The retorque allows for an increase in the stability of the union between the screw and the prosthetic component, and this step is indicated for both single and multiple prostheses [18].

The higher the screw torque, the smaller the formation of micro gaps at the implant-abutment interface, but the greater the residual stress, which reduces the fatigue life of the implant. To reduce this tension, the use of systems with a larger contact surface between the implant and the prosthetic abutment is indicated. [2]. In the present study, the screws were torqued to $10 \mathrm{Ncm}$ and after 10 minutes they were retightened with the initial torque. In this study, the ISO 14801:2016 standards for dynamic fatigue testing for endosseous dental implants were followed. The standard stands up that the specimen must be fixed at a distance of $3.0 \mathrm{~mm}$ from the bone level in order to simulate the reabsorption of the peri-implant tissue, and during mechanical cycling, present an inclination of $30^{\circ}$ in relation to the ground [11]. 
In the oral cavity, chewing forces act on prosthetic restorations, promoting mechanical cyclic impulses, which can be simulated in the laboratory by the mechanical cycling machine, which simulates the physiological conditions during mastication. As for the fatigue test, in this study, 2,000,000 cycles were chosen, which simulates approximately 5 years of chewing function [7].

This study compared two different abutments (straight and mini-conical trunnion) of the same type of implant connection (Indexed Morse taper). Despite not showing statistically significant differences, the straight trunnion abutment had a small advantage with regard to screw torque loss when compared to the mini-conical, obtaining values similar to those in the literature [19 ]. Regardless of the type of abutment, the aging factor through mechanical cycling considerably affected torque loss, which corroborates previous studies $[20,21,22]$.

The initial decrease in torque occurs naturally and is related to the friction caused by the prosthetic screw and the internal walls of the implant. The loss of torque after the fatigue test can be caused by micromovements of the prosthetic components due to the loads received on the prosthesis. Even after the settlement effect, it is possible that there is micro-roughness on the surfaces of the components that, with the incidence of loads, can result in wear and, consequently, the loss of preload, causing the screw to loosen [23].

A factor that helps to maintain the torque of the retaining screw is the union of the crowns. When is a single crown, all the load that is applied falls directly on the abutment and then into the implant and supporting bone tissue. The most affected component is the retention screw, which in many cases causes loosening or even fracture. In joint crowns, on the other hand, the stress distribution occurs more uniformly, causing lower stress concentrations on the prosthetic screw and reducing the chance of loosening and failure of the prosthesis $[1,2,24]$.

Although the results showed that there are no statistical differences in screw torque loss when comparing mini conical and straight trunnion abutments, the use in clinical practice must be evaluated with awareness. Even with the standardization of the tests performed in this in vitro study, there are still limitations and new laboratory, and clinical trials that must be performed to assess the retention screw removal torque in different types of prosthesis after aging, antagonist materials and temperature variation to improve the understanding of this topic.

\section{Conclusions}

Based on the results obtained, it can be concluded that there were no differences to the screw removal torque when comparing mini conical abutments and straight trunnion for Morse taper implants. In addition, the implants tightening sequence did not affect the torque level when two-element splinted prosthesis is considered.

Author Contributions: Conceptualization, L.J.N.N.; T.S.Q.; and T.J.A.P.J.; methodology, L.J.N.N.; L.C.L.G.; and T.S.Q.; formal analysis, L.J.N.N.; L.C.L.G.; and T.S.Q.; investigation, L.J.N.N.; L.C.L.G.; and T.S.Q.; resources, L.J.N.N.; and T.J.A.P.J; data curation, L.C.L.G.; and T.S.Q; writing-original draft preparation, L.J.N.N.; L.C.L.G.; and T.S.Q.; writing-review and editing, T.J.A.P.J.; supervision, T.J.A.P.J.; project administration, L.J.N.N.; and T.J.A.P.J. All authors have read and agreed to the published version of the manuscript.

Funding: This research received no external funding.

Institutional Review Board Statement: Not applicable.

Informed Consent Statement: Not applicable.

Data Availability Statement: Data Available on request.

Conflicts of Interest: The authors declare no conflict of interest. 


\section{References}

1. Silveira, M.; Campaner, L.; Bottino, M.; Nishioka, R.; Borges, A.; Tribst, J.P. Influence of the dental implant number and load direction on stress distribution in a 3-unit implant-supported fixed dental prosthesis. Dent. Med. Probl. 2021, 58, 69-74.

2. Tribst, J.P.M.; Dal Piva, A.M. de O.; da Silva-Concílio, L.R.; Ausiello, P.; Kalman, L. Influence of implant-abutment contact surfaces and prosthetic screw tightening on the stress concentration, fatigue life and microgap formation: A finite element analysis. Oral 2021, 1 , $88-101$.

3. Bernardes, S.R.; da Gloria Chiarello de Mattos, M.; Hobkirk, J.; Ribeiro, R.F. Loss of preload in screwed implant joints as a function of time and tightening/untightening sequences. Int. J. Oral Maxillofac. Implants 2014, 29, 89-96.

4. Adolfi, D.; Mendes Tribst, J.P.; Souto Borges, A.L.; Bottino, M.A. Torque maintenance capacity, vertical misfit, load to failure, and stress concentration of Zirconia restorations cemented or notched to titanium bases. Int. J. Oral Maxillofac. Implants 2020, 35, 357-365.

5. Tonin, B.S.H.; He, Y.; Ye, N.; Chew, H.P.; Fok, A. Effects of tightening torque on screw stress and formation of implant-abutment microgaps: A finite element analysis. The Journal of Prosthetic Dentistry 2021.

6. de Carvalho, B.A.C.; Vedovatto, E.; de Carvalho, P.S.P.; Mazaro, J.V.Q.; Falcón-Antenucci, R.M. Effect of mechanical cycling on screw torque in external hexagon implants with and without platform switching. Braz. Dent. J. 2015, 26, 284-287.

7. Gehrke, S.A.; Pereira, F. de A. Changes in the abutment-implant interface in Morse taper implant connections after mechanical cycling: a pilot study. Int. J. Oral Maxillofac. Implants 2014, 29, 791-797.

8. Martins, C.M.; Ramos, E.V.; Kreve, S.; de Carvalho, G.A.P.; Franco, A.B.G.; de Macedo, L.G.S.; Silva, A. de M.; Dias, S.C. Reverse torque evaluation in indexed and nonindexed abutments of Morse Taper implants in a mechanical fatigue test. Dent. Res. J.

(Isfahan) 2019, 16, 110-116.

9. Schmitt, C.M.; Nogueira-Filho, G.; Tenenbaum, H.C.; Lai, J.Y.; Brito, C.; Döring, H.; Nonhoff, J. Performance of conical abutment (Morse Taper) connection implants: a systematic review: Performance of Conical Implant-Abutment Connection Systems. J. Biomed. Mater. Res. A 2014, 102, 552-574.

10. Mishra, S.K.; Chowdhary, R.; Kumari, S. Microleakage at the different implant abutment interface: A systematic review. J. Clin. Diagn. Res. 2017, 11, ZE10-ZE15.

11. Thomé, G.; Torres Gomes, A.F.; de Moura, M.B.; Felippi, C.; Trojan, L.C. Evaluation of the mechanical reliability of different implantabutment connections for single crowns according to the ISO 14801 fatigue test protocol. Int. J. Oral Maxillofac. Implants 2021, 36, 4754.

12. Varvara, G.; Sinjari, B.; Caputi, S.; Scarano, A.; Piattelli, M. The relationship between time of re-tightening and preload loss of abutment screws for two different implant designs: An in-vitro study. J. Oral Implantol. 2019, 0000-0000.

13. Winkler, S.; Ring, K.; Ring, J.D.; Boberick, K.G. Implant screw mechanics and the settling effect: An overview. J. Oral Implantol. 2003, 29, 242-245.

14. Sakaguchi, R.L.; Borgersen, S.E. Nonlinear contact analysis of preload in dental implant screws. Int. J. Oral Maxillofac. Implants 1995, 10, 295-302.

15. Xu, Y.; Li, W.; Su, M. Clinical assessment of preload maintenance in the abutment screws of single posterior implants after 1 month of use. Int. J. Oral Maxillofac. Implants 2021, 36, 177-181.

16. Kim, K.-S.; Han, J.-S.; Lim, Y.-J. Settling of abutments into implants and changes in removal torque in five different implant-abutment connections. Part 1: Cyclic loading. Int. J. Oral Maxillofac. Implants 2014, 29, 1079-1084.

17. Huang, Y.; Wang, J. Mechanism of and factors associated with the loosening of the implant abutment screw: A review. J. Esthet. Restor. Dent. 2019, 31, 338-345.

18. Spazzin, A.O.; Henrique, G.E.P.; Nóbilo, M.A. de A.; Consani, R.L.X.; Correr-Sobrinho, L.; Mesquita, M.F. Effect of retorque on loosening torque of prosthetic screws under two levels of fit of implant-supported dentures. Braz. Dent. J. 2010, 21, 12-17. 
19. de Oliveira Silva, T.S.; Mendes Alencar, S.M.; da Silva Valente, V.; de Moura, C.D.V.S. Effect of internal hexagonal index on removal torque and tensile removal force of different Morse taper connection abutments. J. Prosthet. Dent. 2017, 117, 621-627.

20. Tribst, J.P.M.; de Melo, R.M.; Borges, A.L.S.; de Assunção E Souza, R.O.; Bottino, M.A. Mechanical behavior of different micro conical abutments in fixed prosthesis. Int. J. Oral Maxillofac. Implants 2018, 33, 1199-1205.

21. Gomes, É.A.; Tiossi, R.; Faria, A.C.L.; Rodrigues, R.C.S.; Ribeiro, R.F. Torque loss under mechanical cycling of long-span zirconia and titanium-cemented and screw-retained implant-supported CAD/CAM frameworks. Clin. Oral Implants Res. 2014, 25, $1395-1402$.

22. Pardal-Pelaez, B.; Montero, J. Preload loss of abutment screws after dynamic fatigue in single implant-supported restorations. A systematic review. J. Clin. Exp. Dent. 2017, 0-0.

23. Theoharidou, A.; Petridis, H.P.; Tzannas, K.; Garefis, P. Abutment screw loosening in single-implant restorations: a systematic review. Int. J. Oral Maxillofac. Implants 2008, 23, 681-690.

24. Tribst, J.P.M.; Rodrigues, V.A.; Borges, A.L.S.; Lima, D.R. de; Nishioka, R.S. Validation of a simplified implant-retained cantilever fixed prosthesis. Implant Dent. 2018, 27, 49-55. 